\title{
Pengaruh Good Corporate Governance pada Kinerja LPD dengan Budaya Organisasi
}

Berorientasi Tim sebagai Variabel Mediasi

\author{
Ni Putu Gita Darmayanti ${ }^{1}$ \\ Fakultas Ekonomi dan Bisnis \\ Universitas Udayana, Indonesia
}

Ayu Aryista Dewi ${ }^{3}$

Fakultas Ekonomi dan Bisnis

Universitas Udayana, Indonesia

\author{
Ni Made Dwi Ratnadi ${ }^{2}$ \\ Fakultas Ekonomi dan Bisnis \\ Universitas Udayana, Indonesia \\ Gerianta Wirawan Yasa ${ }^{4}$ \\ Fakultas Ekonomi dan Bisnis \\ Universitas Udayana, Indonesia
}

Surel : gita.darmayanti98@gmail.com

ABSTRAK

Penelitian ini bertujuan untuk memperoleh bukti empiris pengaruh GCG pada kinerja LPD, pengaruh GCG pada budaya organisasi berorientasi tim, pengaruh budaya organisasi berorientasi tim pada kinerja LPD, menguji budaya organisasi berorientasi tim sebagai pemediasi hubungan antara GCG pada kinerja LPD. Populasi penelitian adalah sebanyak 50 LPD SeKecamatan Penebel, Tabanan. Sampel ditentukan dengan metode nonprobability sampling dengan teknik purposive sampling, diperoleh sebanyak 25 LPD. Teknik analisis data adalah analisis jalur. Hasil analisis menunjukkan GCG berpengaruh positif pada kinerja LPD. GCG berpengaruh positif pada budaya organisasi berorientasi tim. Budaya organisasi berorientasi tim berpengaruh positif pada kinerja LPD. Budaya organisasi berorientasi tim memediasi sebagian pengaruh GCG pada kinerja LPD.

Kata Kunci: Good Corporate Governance; Budaya Organisasi Berorientasi Tim; Kinerja Lembaga Perkreditan Desa.

The Effect of Good Corporate Governance on the Performance of LPD with Team-Oriented Organizational Culture as a Mediating Variable

\section{ABSTRACT}

This research was aims to obtain to empirical evidence of the influence of GCG on the performance of LPD, the effect of GCG on team-oriented organizational culture, the influence of team-oriented organizational culture on LPD performance, examine the culture of team-oriented organizations as mediating the relationship between GCG on LPD performance. The research population was 50 LPD in Penebel, Tabanan. The sample was determined by the nonprobability sampling method with a purposive sampling technique, obtained as many as 25 LPD. The data are analyzed using path analysis. The analysis shows that GCG has a positive effect on LPD performance. GCG has a positive effect on teamoriented organizational culture. Team-oriented organizational culture has a positive effect on LPD performance. Team-oriented organizational culture mediates a part of the influence of GCG on LPD performance.

Keywords: Good Corporate Governance; Team-Oriented Organizational Culture; Performance of Lembaga Perkreditan Desa.

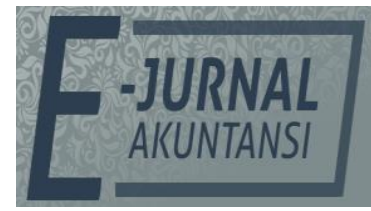

e-ISSN 2302-8556

Vol. 30 No. 10

Denpasar, Oktober 2020

Hal. 2471-2486

DOI:

10.24843/EJA.2020.v30.i10.p03

PENGUTIPAN:

Darmayanti, N. P. G., Ratnadi, N. M. D., Dewi, A.

A. \& Yasa, G. W.

(2020). Pengaruh Good

Corporate Governance pada Kinerja LPD dengan Budaya Organisasi Berorientasi Tim sebagai Variabel Mediasi. EJurnal Akuntansi, 30(10), 2471-2486

RIWAYAT ARTIKEL: Artikel Masuk: 21 Juni 2020 Artikel Diterima: 26 Juli 2020

Artikel dapat diakses : https://ojs.unud.ac.id/index.php/Akuntansi/index 


\section{PENDAHULUAN}

Indonesia memiliki usaha mikro kecil dan menengah (UMKM) yang memberikan dampak besar dalam pembangunan ekonomi karena UMKM memberikan PDB hingga 60,34\% (Putra, 2018). Lembaga Keuangan di Indonesia terbagi menjadi dua yaitu lembaga keuangan bank dan lembaga keuangan non bank. Salah satu yang termasuk dalam lembaga keuangan non bank di Bali yang berkontribusi pada UMKM adalah Lembaga Perkreditan Desa (LPD). LPD dalam memberikan kredit prosesnya lebih mudah dan tidak berbelit-belit seperti lembaga keuangan bank (Yudana et al., 2015). Meskipun LPD dapat dikatakan berkembang pesat sehingga dipuji oleh berbagai pihak, namun masih terdapat LPD yang berada dalam kondisi bermasalah dan bangkrut (Atmadja et al., 2014). LPD yang bermasalah biasanya dilihat dari kinerja keuanganya yang rendah (Yasa et al., 2018). Dari data yang diperoleh dalam rapat pansus ranperda revisi perda LPD yang dipimpin oleh I Nyoman Parta menyatakan bahwa dari 1.433 LPD yang ada di Bali, yang berada dalam keadaan baik 909 LPD, cukup baik 204 LPD, kurang baik 124 LPD, tidak baik 38 LPD, dan bangkrut 158 LPD (Edison, 2017). Mengenai jumlah LPD setiap Kabupaten di Provinsi Bali tahun 2018 dapat dilihat pada Tabel 1.

Tabel 1. Jumlah LPD Setiap Kabupaten/Kota di Provinsi Bali Tahun 2018

\begin{tabular}{|c|c|c|}
\hline No & Kabupaten/Kota & Jumlah LPD \\
\hline 1 & Denpasar & 35 \\
\hline 2 & Badung & 122 \\
\hline 3 & Buleleng & 169 \\
\hline 4 & Jembrana & 64 \\
\hline 5 & Tabanan & 307 \\
\hline 6 & Gianyar & 270 \\
\hline 7 & Bangli & 159 \\
\hline 8 & Klungkung & 119 \\
\hline \multirow[t]{2}{*}{9} & Karangasem & 190 \\
\hline & Total & 1435 \\
\hline
\end{tabular}

Sumber: LPLPD Provinsi Bali, 2018

Kabupaten Tabanan merupakan kabupaten terbanyak yang memiliki LPD yaitu 307 buah LPD. Posisi pertama LPD yang bangkrut yaitu LPD Tabanan dengan jumlah 54 LPD. Mengenai jumlah LPD setiap Kecamatan di Kabupaten Tabanan yang masih aktif tahun 2018 dapat dilihat pada Tabel 2.

Tabel 2. Jumlah LPD Setiap Kecamatan di Kabupaten Tabanan Tahun 2018

\begin{tabular}{clc}
\hline No & \multicolumn{1}{c}{ Kecamatan } & Jumlah LPD \\
\hline 1 & Pupuan & 19 \\
2 & Selemadeg Barat & 28 \\
3 & Selemadeg Telemadeg Timur & 22 \\
4 & Selembitan & 19 \\
5 & Kerambin & 26 \\
6 & Tabanan & 12 \\
7 & Kediri & 21 \\
8 & Marga & 22 \\
9 & Penebel & 50 \\
10 & Baturiti & 28 \\
& Total & 247 \\
\hline
\end{tabular}

Sumber: LPLPD Kabupaten Tabanan, 2018 
Dari sepuluh kecamatan di Kabupaten Tabanan, Kecamatan penebel adalah salah satu wilayah yang menjadi pusat pembangunan tabanan utara dengan peringkat LPD terbanyak pertama di Kabupaten Tabanan, yaitu 50 LPD dari 18 Desa Adat yang ada.

Suatu kasus yang menjadi sorotan LPD di Kabupaten Tabanan adalah kasus dari LPD Desa Pekraman Sunantaya, Kecamatan Penebel, Tabanan yang mengalami kerugian hingga Rp. 1,4 miliar (Jingga, 2018). Permasalahan hilang dana nasabah mencapai Rp. 1,4 miliar di LPD sunantaya disebabkan kurang baiknya pengelolaan dana nasabah oleh pegawai LPD dan adanya kasus manipulasi. Pencegahan terhadap praktik-praktik yang tidak sehat pada LPD seharusnya dapat dilakukan jika badan pengawas LPD tanggap dalam menemukan adanya transaksi yang mencurigakan (Widyantara et al., 2017). Terkait permasalahan tersebut, maka perlu diimplementasikan prinsip good corporate governance (Sanchia \& Zen, 2015). LPD akan memiliki kemampuan sistem pengendalian internal yang baik ditunjukkan dengan penerapan prinsipprinsip GCG yang baik untuk meraih kembali kepercayaan masyarakat serta dilihat dari bagaimana peningkatan kinerja LPD setiap tahun. Peningkatan kinerja LPD setiap tahunnya dapat dilihat dari pengukuran kinerja LPD seperti kinerja keuangan pada laporan keuangan dan kinerja manajemen pada kualitas layanan.

Pengukuran kinerja organisasi perlu dilakukan untuk mengetahui pencapaian kinerja organisasi tersebut setiap tahunnya (Satriyadi \& Suryanawa, 2015). Penilaian kinerja diperlukan oleh LPD untuk mengukur efektivitas dan efisiensi dari operasional kegiatan yang dilakukannya terutama menyangkut bagian kredit (Wedantara \& Adi, 2019). Dengan penerapan GCG akan membantu meningkatkan dan memelihara kinerja keuangan LPD (Yuliantari et al., 2020). Kinerja keuangan digunakan untuk membandingkan kinerja saat ini dengan kinerja di masa lalu (Sandraningsih \& Putri, 2015). Pengukuran kinerja organisasi sebaiknya tidak hanya diukur dengan menggunakan aspek keuangan saja, tetapi juga harus mempertimbangkan beberapa aspek non keuangan (Supriyatna et al., 2018). Aspek keuangan dapat dilihat dari laporan keuangan, sedangkan aspek non keuangan dapat dilihat dari perspektif konsumen, perspektif bisnis internal, perspektif pertumbuhan dan pembelajaran. Perspektif menentukan hal apa yang ingin dicapai oleh organisasi (Ege \& Sener, 2017).

Penelitian tentang GCG dan kinerja sudah ada yang melakukan, menurut penelitian Risqiyah et al., (2014) menyatakan bahwa prinsip GCG tidak berpengaruh pada kinerja keuangan, sedangkan menurut Putri et al., (2017), Puspitha \& Sujana (2016) menyatakan penerapan GCG adanya hubungan positif dan berpengaruh dengan kinerja berbasis balance scorecard. Namun berbeda dengan hasil penelitian Zaidirina \& Lindrianasari (2015), Hapsari (2018) yang menyatakan bahwa prinsip-prinsip good corporate governance tidak berpengaruh dan tidak signifikan pada kinerja. Hal tersebut masih menunjukan belum adanya konsistensi pendapat namun sudah ada yang mampu menunjukkan hubungan antara variabel tersebut namun belum cukup, maka diperlukan hubungan dua variabel yang berkaitan secara kausal dengan menambahkan variabel mediasi.

LPD merupakan sebuah organisasi keuangan non bank yang memiliki keyakinan terhadap kinerjanya yang mendapat pengaruh nilai yang berasal dari 
kekuatan diri, lingkungan kerja, serta hubungan antar sesama pegawai (Adiputra, 2014). LPD diharapkan mempertimbangkan suatu budaya organisasi yang dapat dijadikan panduan bagi setiap organisasi (Astini \& Yadnyana, 2019). Budaya organisasi akan memberikan suasana psikologi untuk semua pegawai organisasi (Pratami \& Damayanthi, 2018). Budaya organisasi yang kuat berguna sebagai mengarahkan perilaku karyawan (Paramita et al., 2018). LPD melakukan kegiatan operasional antar pegawainya menggunakan budaya kerjasama antar tim yaitu dipengaruhi oleh harmonisnya lingkungan kerja dan hubungan antar pegawai yang didasarkan sesuai dengan awig-awig, pararem desa dan peraturan daerah karena LPD dilandasi oleh hukum adat. Hal ini sejalan dengan penelitian Jepkorir et al., (2017) yang menyatakan Budaya organisasi berorientasi tim memberikan pengaruh positif pada kinerja perbankan. Menurut Puspitha \& Sujana (2016), Soraya \& Suardana (2018) faktor lain yang berpengaruh terhadap kinerja dan good corporate governance adalah budaya organisasi. Karena hal tersebut peneliti menambahkan variabel budaya organisasi berorientasi tim sebagai variabel mediasi. LPD pada hakekatnya adalah sebuah organisasi keuangan non bank yang operasional kinerjanya dipengaruhi oleh budaya berorientasi tim yaitu hubungan antar pegawai, lingkungan kerja, kerjasama tim yang di dasari atas hukum adat. Semakin baik budaya organisasi berorientasi tim diterapkan di LPD dan didukung oleh tata kelola yang baik maka semakin meningkatkan kinerja LPD

Teori keagenan (agency theory) merupakan landasan hal dasar yang digunakan untuk menjelaskan konsep good corporate governance. Dalam penelitian ini, pemilik dari LPD yaitu desa adat sebagai principal, melimpahkan wewenang pengelolaan LPD kepada karyawan LPD sebagai agent dengan adanya kontrak. Adanya pelimpahan wewenang dari principal ke agent ini, telah menimbulkan adanya hubungan keagenan.

Teori stewardship menggambarkan hubungan antara pemilik (principal) dan manajer (steward). Teori ini ada karena asumsi filosofis mengenai sifat manusia yakni manusia pada hakekatnya dapat dipercaya, mampu bertindak dengan penuh tanggung jawab, mempunyai integritas dan kejujuran terhadap pihak lain (Putri \& Ulupui, 2017). Dalam penelitian ini, diharapkan dapat menjelaskan bahwa pengelola LPD (steward) dalam mengoperasikan LPD akan mengesampingkan kepentingan pribadi mereka dan memaksimalkan kinerjanya untuk mencapai tujuan LPD.

Faktor penting dalam menentukan nilai organsiasi dan berpengaruh pada kinerja LPD yaitu GCG (Setyawan \& Putri, 2013). Pemilik dari LPD yaitu desa adat sebagai principal, melimpahkan wewenang pengelolaan LPD kepada karyawan LPD sebagai agent dengan adanya kontrak kerja sehingga menyebabkan adanya hubungan keagenan, hal ini sesuai dengan teori keagenan. Dengan adanya hubungan keagenan akan menimbulkan konflik keagenan dan hal ini dapat diminimalisir dengan menerapkan prinsip good corporate governance. Hasil penelitian Kusumasari et al., (2017), Puspitha \& Sujana (2016) menyatakan bahwa penerapan good corporate governance memberikan pengaruh yang positif dan signifikan terhadap kinerja keuangan LPD. Good corporate governance di LPD akan berjalan dengan baik bila diawasi oleh dewan pengawas LPD (Suaryana \& 
Noviari, 2018). Berdasarkan uraian tersebut, maka dapat dirumuskan hipotesis sebagai berikut.

$\mathrm{H}_{1}$ : Good corporate governance berpengaruh positif pada kinerja LPD.

Good corporate governance merupakan suatu pedoman dan sistem dalam mengelola perusahaan yang baik demi tercapainya keseimbangan kepentingan stakeholder. Good Corporate Governance (GCG) adalah salah satu elemen kunci dalam peningkatan efisiensi ekonomi suatu organisasi (Dasuki \& Lestari, 2019), serta tata kelola perusahaan yang mematuhi hukum dan etika masyarakat (Mudashiru et al., 2014). Good corporate governance memberikan suatu pedoman yang baik kepada budaya organisasi berorientasi tim karena GCG bisa memberikan suatu arahan dan didukung oleh teori stewardship dengan karyawan sehingga karyawan akan memiliki motivasi meningkatkan budaya organisasi berorientasi tim. Penelitian Soraya \& Suardana (2018) menyatakan bahwa terdapat pengaruh GCG pada budaya organisasi. Hal ini sejalan dengan penelitian Sanjaya et al., (2019), Indriyani \& Putra (2015), dan Puspitha \& Sujana (2016) yang menyatakan adanya pengaruh positif antara GCG dengan budaya organisasi. Budaya organisasi berorientasi tim berpengaruh signifikan terhadap suatu perkembangan organisasi (Hakim, 2015). Berdasarkan uraian tersebut, maka dapat dirumuskan hipotesis sebagai berikut.

$\mathrm{H}_{2}$ : Good corporate governance berpengaruh positif pada budaya organisasi berorientasi tim.

LPD merupakan sebuah organisasi non keuangan bank yang memilki keyakinan terhadap kinerjanya yang mendapat pengaruh nilai yang berasal dari kekuatan diri, lingkungan kerja, serta hubungan antar sesama pegawai (Adiputra, 2014). LPD merupakan organisasi mengutamakan kekompakan tim didalam melaksanakan kegiatan serta memberikan imbalan dan hukuman berdasarkan kelompok dan bukan berdasarkan individu. Penerapannya dalam organisasi dengan dukungan manajemen pada karyawan untuk bekerja sama dalam satu tim, (Ratnadi et al., 2017). Hal ini sesuai dengan teori penatalayanan yang menggambarkan manajer bertanggungjawab. Penelitian yang dilakukan Putri et al., (2017), Anggiriawan \& Wirakusuma (2015) menyatakan bahwa budaya organisasi berpengaruh positif dan signifikan terhadap kinerja perusahaan. Berdasarkan uraian tersebut, maka dapat dirumuskan hipotesis sebagai berikut.

$\mathrm{H}_{3}$ : Budaya organisasi orientasi tim berpengaruh positif pada kinerja LPD.

LPD akan mempunyai kekuatan struktur pengendalian internal yang baik diperlihatkan dengan penerapan prinsip-prinsip GCG yang baik untuk meraih kembali kepercayaan masyarakat serta dilihat dari bagaimana peningkatan kinerja LPD setiap tahun. Peningkatan kinerja LPD setiap tahunnya dapat dilihat dari pengukuran kinerja LPD. LPD perlu mempertimbangkan budaya organisasi yang dapat dijadikan panduan bagi setiap organisasi (Astini \& Yadnyana, 2019). LPD melakukan kegiatan operasional antar pegawainya menggunakan budaya kerjasama antar tim yaitu dipengaruhi oleh harmonisnya lingkungan kerja dan hubungan antar pegawai yang didasarkan sesuai dengan awig-awig. Budaya organisasi penting bagi organisasi karena kelangsungan organisasi tergantung pada kepuasan pelanggan dalam mendapatkan pelayanan yang baik dan kinerja yang baik (Dimitrios, 2014). Tindakan kecurangan pada 
LPD dapat terjadi karena adanya asimetri informasi karena terjadi pelimpahan tugas dari principal ke agent sehingga menimbulkan adanya hubungan keagenan dan hal ini dapat diminimalisir dengan tata kelola yang baik dengan dukungan budaya organisasi yang baik. Menurut Soraya \& Suardana (2018), Puspitha \& Sujana (2016) menyatakan faktor lain yang berpengaruh terhadap good corporate governance adalah budaya organisasi. Penelitian yang dilakukan Hakim (2015) menyatakan bahwa budaya organisasi orientasi tim berpengaruh positif dan signifikan pada kinerja karyawan. Sejalan dengan penelitian Madueke \& Emerole (2017), Kamau \& Wanyoike (2019) menyatakan bahwa budaya organisasi berpengaruh positif dan signifikan pada kinerja. Berdasarkan uraian tersebut, maka dapat dirumuskan hipotesis sebagai berikut.

$\mathrm{H}_{4}$ : Budaya organisasi berorientasi tim memediasi pengaruh good corporate governance pada kinerja LPD.

\section{METODE PENELITIAN}

Penelitian ini merupakan penelitian asosiatif dengan bentuk hubungan kausalitas dan menggunakan pendekatan kualitatif yang dikuantitatifkan. Penelitian ini menguji pengaruh GCG pada kinerja lembaga perkreditan desa dengan budaya organisasi berorientasi tim sebagai variabel mediasi. Penelitian ini dilakukan pada Lembaga Perkreditan Desa Se-Kecamatan Penebel, Kabupaten Tabanan. Objek penelitian dalam penelitian ini adalah kinerja Lembaga Perkreditan Desa (LPD) yang di prediksi dengan GCG dan budaya organisasi berorientasi pada tim.

Variabel terikat dalam penelitian ini adalah kinerja LPD (Y) yang diukur dengan menggunakan 4 perspektif yaitu (1) perspektif keuangan. (2) perspektif customer. (3) perspektif bisnis internal. (4) perspektif pembelajaran dan pertumbuhan. Variabel bebas dalam penelitian ini adalah good corporate governance $\left(X_{1}\right)$ yang diukur dengan menggunakan indikator prinsip-prinsip good corporate governance yaitu (1) transparansi. (2) akuntabilitas. (3) responsibilitas. (4) independensi. (5) kewajaran. Variabel mediasi dalam penelitian ini adalah budaya organisasi berorientasi tim $\left(X_{2}\right)$ yang diukur dengan menggunakan indikator yaitu (1) menyelesaikan pekerjaan dengan kerjasama tim. (2) menolong sesama angota kerja bila ada yang mengalami kesulitan. (3) Loyalitas terhadap tim sangat tinggi. (4) Permasalahan di tempat kerja, selalu diselesaikan secara bersama-sama. (5) Koordinasi dengan rekan kerja dan pimpinan. Tiap-tiap jawaban diukur dengan menggunakan skala likert lima poin, yaitu skor 1 = sangat tidak setuju (STS), skor 2 = tidak setuju (TS), skor 3 = kurang setuju (KS), skor 4 = setuju (S), skor 5 = sangat setuju (SS).

Populasi dalam penelitian ini adalah LPD Se-Kecamatan Penebel, Tabanan. Metode penentuan sampel yang digunakan dalam penelitian ini adalah purposive sampling. Adapun kriteria-kriteria yang digunakan dalam penelitian sampel yaitu (1) ketua dan pegawai LPD minimal sudah berkerja selama 2 tahun di LPD. (2) pegawai memiliki pengetahuan tentang kinerja keuangan di LPD. (3) pegawai memiliki pengetahuan tentang kegiatan manajemen di LPD. Sampel dalam penelitian ini adalah adalah ketua LPD dan 3 pegawai LPD yang 
memenuhi kriteria-kriteria yang sudah di tentukan. Metode pengumpulan data yang digunakan dalam penelitian ini adalah kuesioner.

Teknik analisis data yang digunakan dalam penelitian ini adalah analisis jalur (path analysis), dikarenakan pengaruh pengujian variabel independen pada variabel dependen menggunakan variabel penghubung yaitu variabel mediasi. Penyusunan model juga dapat dinyatakan dalam bentuk persamaan diagram jalur yaitu sebagai berikut.

Persamaan Sub-struktural 1

$$
X_{2}=\beta_{1} X_{1}+\varepsilon_{1}
$$

Persamaan Sub-struktural 2

$$
Y=\beta_{2} X_{2}+\beta_{3} X_{3}+\varepsilon_{2} \text {. }
$$

Keterangan:

$\mathrm{Y}=$ Kinerja LPD

$\mathrm{X}_{1}=$ Good Corporate Governance

$\mathrm{X}_{2}=$ Budaya Organisasi Berorientasi Tim

$\beta_{1}=$ Koefisien regresi jalur $X_{1}$ dengan $X_{2}$

$\beta_{2}=$ Koefisien regresi jalur $X_{1}$ dengan $Y$

$\beta_{3}=$ Koefisien regresi jalur $X_{2}$ dengan $Y$

$\varepsilon=$ error

\section{HASIL DAN PEMBAHASAN}

Populasi penelitian ini adalah LPD yang ada di Kecamatan Penebel, Tabanan. LPD yang diteliti adalah LPD yang aktif dengan jumlah 50 LPD. Dari 50 LPD yang menjadi populasi, penelitian ini menggunakan 25 LPD sebagai sampel yang ditentukan melalui teknik purposive sampling dengan memasukkan kriteriakriteria yang sesuai dengan penelitian. Proses seleksi sampel ini dapat dilihat pada Tabel 3.

Tabel 3. Proses Seleksi Sampel

\begin{tabular}{lc}
\hline \multicolumn{1}{c}{ Kriteria } & Jumlah LPD \\
\hline LPD yang aktif pada tahun 2019-2020 & 50 \\
LPD yang bermasalah pada tahun 2019-2020 & $(1)$ \\
LPD yang memiliki karyawan berkerja kurang dari 2 tahun & $(0)$ \\
LPD yang tidak memiliki jumlah karyawan lebih dari 3 orang & $(24)$ \\
dibagian keuangan dan manajemen & \\
Total LPD yang dijadikan sampel & 25 \\
Total Responden & 100 \\
\hline
\end{tabular}

Sumber: Data Penelitian, 2020

Statistik deskriptif merupakan hasil analisis yang digunakan untuk melihat nilai data minimum, maksimum, rata-rata (mean), dan deviasi standar dari masing-masing variabel penelitian. Statistik deskriptif dalam penelitian ini digunakan untuk memberikan informasi, mendeskripsikan data atau gambaran data mengenai variabel-variabel penelitian yaitu good corporate governance, budaya organisasi berorientasi tim, dan kinerja LPD secara umum dilihat dari minimum, maksimum, rata-rata (mean), dan deviasi standar masing-masing variabel. Hasil analisis statistik deskriptif dalam penelitian ini dapat dilihat pada Tabel 4 . 
Tabel 4. Hasil Statistik Deskriptif Variabel Penelitian

\begin{tabular}{lccccc}
\hline & $\mathrm{N}$ & Minimum & Maximum & Mean & Std. Deviation \\
\hline $\begin{array}{l}\text { Good Corporate } \\
\text { Governance (X1) }\end{array}$ & 100 & 1 & 5 & 4,39 & 6,585 \\
$\begin{array}{l}\text { Budaya Organisasi } \\
\text { Berorientasi Tim (X2) }\end{array}$ & 100 & 3 & 4 & 4,40 & 3,968 \\
Kinerja LPD (Y) & 100 & 1 & 4 & 4,33 & 4,445 \\
\hline
\end{tabular}

Sumber: Data Penelitian, 2020

Nilai minimum good corporate governance adalah 1 yang berarti responden sangat tidak setuju pada keputusan ketua yang objektif dan nilai maksimunnya adalah 5. Nilai mean untuk variabel good corporate governance adalah 4,39 dan standar deviasi sebesar 6,585. Nilai minimum budaya organisasi berorientasi tim adalah 3 yang berarti responden kurang setuju pada menyelesaikan pekerjaan dengan kerjasama tim, loyalitas terhadap tim sangat tinggi, koordinasi dengan rekan kerja dan nilai maksimunnya adalah 5 . Nilai mean untuk variabel budaya organisasi berorientasi tim adalah 4,40 dan standar deviasi sebesar 3,968. Nilai minimum kinerja LPD adalah 1 yang berarti responden sangat tidak setuju dengan frekuensi peningkatan nasabah, keluhan nasabah terhadap pengelola LPD dan nilai maksimunnya adalah 5 . Nilai mean untuk variabel kinerja LPD adalah 4,33 dan standar deviasi sebesar 4,445.

Uji instrumen penelitian dilakukan untuk memastikan bahwa kuesioner yang digunakan merupakan kuesioner yang relevan. Hasil uji instrumen validitas memiliki skor lebih dari sama dengan 0,30. Hasil uji validitas menyatakan bahwa hasil korelasi terkecil yaitu 0,361 dan korelasi terbesar yaitu 0,836 . Hal tersebut menunjukkan bahwa kuesioner dikatakan valid dan layak digunakan sebagai instrumen penelitian. Hasil uji instrumen reliabilitas adalah koefisien Alpha Cronbach lebih dari 0,70. Jadi dapat dinyatakan bahwa seluruh variabel telah memenuhi syarat reliabilitas atau kehandalan sehingga dapat digunakan untuk melakukan penelitian.

Uji asumsi klasik dilakukan untuk memastikan bahwa model regresi yang dibuat sudah valid dan layak untuk diteliti. Hasil dari uji asumsi klasik meliputi uji normalitas dan linearitas. Hasil uji normalitas menunjukkan bahwa substruktur 1 sebesar 0,121 dan substruktur 2 sebesar 0,732 yang berarti di atas tingkat signifikansi yang telah ditentukan yaitu 0,05 maka, penelitian berdistribusi normal. Hasil uji linieritas regresi untuk substruktur 1 menunujukkan bahwa tingkat signifikansi sebesar 0,000. Hal ini menggambarkan bahwa pada model regresi substruktur 1 asumsi liniearitas terpenuhi karena Sig. $=0,000<0,05$.

Perhitungan koefisien path atau analisis jalur digunakan untuk menguji pengaruh variabel mediasi yang digunakan dalam penelitian ini. Terdapat variabel yang berperan ganda dalam analisis jalur yaitu sebagai variabel bebas pada suatu hubungan, namun menjadi variabel terikat pada hubungan lain. Perhitungan koefisien path digunakan untuk memastikan bahwa model regresi yang dibuat memiliki hubungan mediasi, mediasi sebagian, atau tidak memiliki hubungan mediasi. Hasil perhitungan koefisien path atau analisis jalur untuk regresi substruktur 1 dan 2 dapat dilihat pada tabel 5, dan tabel 6 . 
Tabel 5. Hasil Uji Analisis Jalur Substruktur 1

\begin{tabular}{|c|c|c|c|c|c|c|}
\hline \multirow{2}{*}{\multicolumn{2}{|c|}{ Model }} & \multicolumn{2}{|c|}{$\begin{array}{l}\text { Unstandardized } \\
\text { Coefficients }\end{array}$} & \multirow{2}{*}{$\begin{array}{c}\begin{array}{c}\text { Standardized } \\
\text { Coefficients }\end{array} \\
\text { Beta }\end{array}$} & \multirow[t]{2}{*}{$\mathrm{t}$} & \multirow[t]{2}{*}{ Sig. } \\
\hline & & B & Std. Error & & & \\
\hline \multirow[t]{6}{*}{1} & (Constant) & 1.905 & 3.248 & & 0,587 & 0,559 \\
\hline & $\begin{array}{l}\text { Good Corporate } \\
\text { Governance }\end{array}$ & 0,480 & 0,037 & 0,796 & 13,011 & 0,000 \\
\hline & R Square & 0,633 & & & & \\
\hline & Adjusted R Square & 0,630 & & & & \\
\hline & F Statistik & 169,293 & & & & \\
\hline & Signifikan Uji F & 0,000 & & & & \\
\hline
\end{tabular}

Sumber: Data Penelitian, 2020

Berdasarkan hasil analisis jalur substruktur 1 seperti yang disajikan pada Tabel 5, maka dapat dibuat persamaan struktural sebagai berikut.

$\mathrm{X} 2=\beta_{1} \mathrm{X}_{1}+\varepsilon_{1}$

$\mathrm{X} 2=0,480 \mathrm{X}_{1}+\varepsilon_{1}$

Nilai constant sebesar 1,905 memiliki arti bahwa bila variabel good corporate governance dianggap 1 maka variabel budaya organisasi berorientasi tim selaku variabel dependen akan tetap ada, namun dengan nilai signifikansi 0,559 yang lebih besar dari 0,05 maka variabel budaya organisasi berorientasi tim tidak signifikan dan perlu dipengaruhi oleh variabel good corporate governance. Nilai koefisien regresi variabel budaya organisasi berorientasi tim bernilai positif dengan nilai signifikansi uji $\mathrm{t}<0,05$. Hal ini menunjukkan bahwa variabel good corporate governance memiliki pengaruh positif yang signifikan terhadap variabel budaya organisasi berorientasi tim. Besarnya pengaruh variabel bebas terhadap variabel terikat yang ditunjukkan oleh nilai determinasi total (Adjusted $R$ Square) sebesar 0,630 mempunyai arti bahwa sebesar 63,0\% variasi budaya organisasi berorientasi tim dipengaruhi oleh variasi good corporate governance, sedangkan sisanya yaitu sebesar 37,0\% dijelaskan oleh faktor lain yang tidak dimasukkan ke dalam model.

Tabel 6. Hasil Uji Analisis Jalur Substruktur 2

\begin{tabular}{|c|c|c|c|c|c|c|}
\hline \multirow{2}{*}{\multicolumn{2}{|c|}{ Model }} & \multicolumn{2}{|c|}{$\begin{array}{l}\text { Unstandardized } \\
\text { Coefficients }\end{array}$} & \multirow{2}{*}{$\begin{array}{c}\begin{array}{c}\text { Standardized } \\
\text { Coefficients }\end{array} \\
\text { Beta }\end{array}$} & \multirow[t]{2}{*}{$\mathrm{t}$} & \multirow{2}{*}{ Sig. } \\
\hline & & B & Std. Error & & & \\
\hline \multirow[t]{7}{*}{1} & (Constant) & 0,278 & 2,654 & & 0,105 & 0,917 \\
\hline & $\begin{array}{l}\text { Good Corporate } \\
\text { Governance }\end{array}$ & 0,335 & 0,050 & 0,496 & 6,746 & 0,000 \\
\hline & $\begin{array}{l}\text { Budaya Organisasi } \\
\text { Berorientasi Tim }\end{array}$ & 0,506 & 0,082 & 0,452 & 6,147 & 0,000 \\
\hline & R Square & 0,808 & & & & \\
\hline & Adjusted R Square & 0,804 & & & & \\
\hline & F Statistik & 203,605 & & & & \\
\hline & Signifikan Uji F & 0,000 & & & & \\
\hline
\end{tabular}

Sumber: Data Penelitian, 2020

Berdasarkan hasil analisis jalur substruktur 2 seperti yang disajikan pada Tabel 6, maka dapat dibuat persamaan struktural sebagai berikut. 
$Y=\beta_{2} X_{2}+\beta_{3} X_{3}+\varepsilon_{2}$

$Y=0,335 X_{2}+0,506 X_{3}+\varepsilon_{2}$

Nilai constant sebesar 0,278 memiliki arti bahwa bila variabel good corporate governance dan budaya organisasi berorientasi tim dianggap 0, maka variabel kinerja LPD selaku variabel dependen akan tetap ada, namun dengan nilai signifikansi 0,917 yang lebih besar dari 0,05 maka variabel kinerja LPD tidak signifikan dan perlu dipengaruhi oleh variabel good corporate governance dan budaya organisasi berorientasi tim. Nilai signifikansi masing-masing variabel bebas < 0,050. Hal ini menunjukkan bahwa semua variabel bebas memiliki pengaruh yang signifikan terhadap variabel terikat. Besarnya pengaruh variabel bebas terhadap variabel terikat yang ditunjukkan oleh nilai determinasi total (Adjusted $R$ Square) sebesar 0,804 mempunyai arti bahwa sebesar $80,4 \%$ variasi kinerja LPD dipengaruhi oleh good corporate governance dan budaya organisasi berorientasi tim, sedangkan sisanya sebesar 19,6\% dijelaskan oleh faktor lain yang tidak dimasukkan ke dalam model.

Pemeriksaan validitas model dalam analisis jalur menggunakan indikator koefsien determinasi total $\left(\mathrm{R}^{2} \mathrm{M}\right)$ dengan terlebih dahulu menghitung nilai standar error dengan perhitungan sebagai berikut.

$$
\begin{aligned}
& P \epsilon_{\mathrm{i}}=\sqrt{1-\mathrm{R}_{\mathrm{i}}{ }^{2}} \\
& \mathrm{P} \epsilon_{1}=\sqrt{1-{R_{1}}^{2}}=\sqrt{1-0,633}=0,367 \\
& \mathrm{P \epsilon}_{2}=\sqrt{1-{R_{2}}^{2}}=\sqrt{1-0,808}=0,192
\end{aligned}
$$

Maka dari itu, nilai koefisien determinasi total $\left(R^{2} M\right)$ adalah sebagai berikut.

$$
\begin{aligned}
\mathrm{R}_{\mathrm{m}}{ }_{\mathrm{m}} & =1-\left(\mathrm{P} \varepsilon_{1}\right)^{2}\left(\mathrm{P} \varepsilon_{2}\right)^{2} \\
& =1-(0,367)^{2}(0,192)^{2} \\
& =1-(0,134)(0,036) \\
& =0,995
\end{aligned}
$$

Nilai determinasi total sebesar 0,995 mempunyai arti bahwa sebesar 99,5\% variasi kinerja LPD dipengaruhi oleh variasi good corporate governance dan budaya organisasi berorientasi tim, sedangkan sisanya sebesar 0,5\% djelaskan oleh faktor lain yang tidak dimasukkan ke dalam model. Perhitungan pengaruh antar variabel diterangkan dalam tabel 7 sebagai berikut.

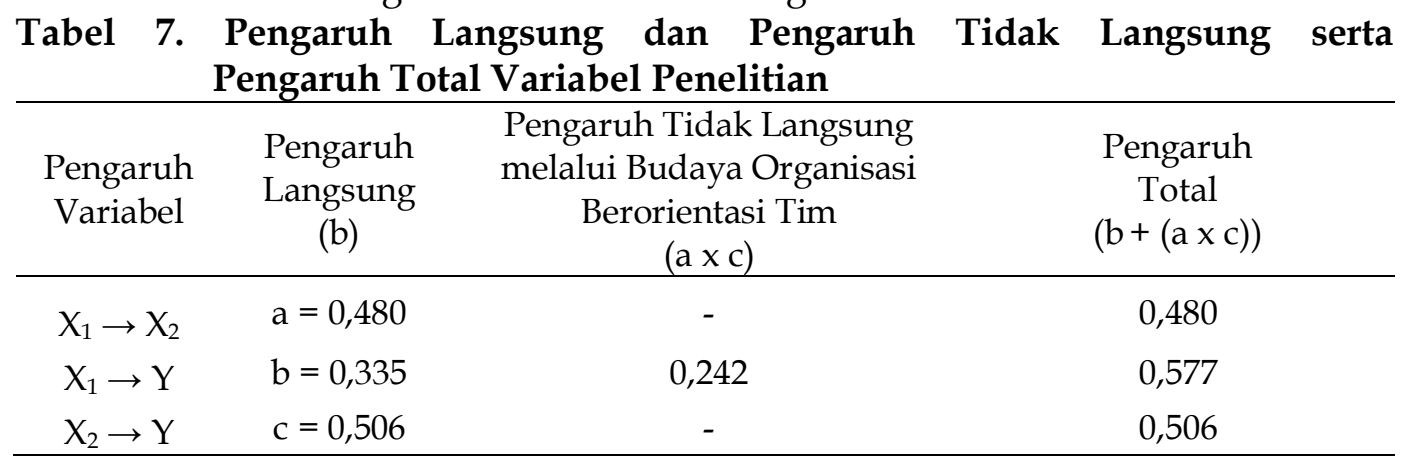

Sumber: Data Penelitian, 2020 
Hipotesis pertama menyatakan good corporate governance berpengaruh pada kinerja LPD. Berdasarkan hasil analisis pengaruh jumlah good corporate governance pada kinerja LPD diperoleh nilai signifikansi sebesar 0,000 dengan nilai koefisien regresi bernilai positif sebesar 0,335. Nilai signifikansi 0,000 lebih kecil dari 0,05 mengindikasikan bahwa $\mathrm{H}_{1}$ diterima. Hal ini berarti bahwa pengaruh good corporate governance berpengaruh positif dan signifikan pada kinerja LPD. Hal ini menunjukkan bahwa apabila LPD menerapkan good corporate governance menyebabkan kinerja LPD semakin baik. Adanya pendelegasian tugas pengelolaan dari desa pekraman kepada pengurus LPD menyebabkan adanya hubungan keagenan dan memungkinkan timbulnya konflik keagenan. Dari hasil analisis menunjukkan adanya GCG akan membuat para nasabah yakin dengan para pengelola yang akan memberikan keuntungan bagi mereka dan pengelola tidak akan menggelapkan dana. Hasil penelitian sejalan dengan hasil penelitian yang dikemukakan oleh Kusumasari et al., (2017), Putri et al., (2017), dan Sawitri \& Ramantha (2018) menyatakan bahwa penerapan GCG memberikan pengaruh positif dan signifikan pada kinerja. Sejalan dengan penelitian Puspitha \& Sujana (2016) juga membuktikan bahwa GCG memberikan pengaruh positif yang signifikan pada kinerja perbankan berbasis balance scorecard.

Hipotesis kedua menyatakan good corporate governance berpengaruh positif pada budaya organisasi beorientasi tim. Berdasarkan hasil analisis pengaruh good corporate governance pada budaya organisasi berorientasi tim diperoleh nilai signifikansi sebesar 0,000 dengan nilai koefisien regresi bernilai positif sebesar 0,480. Nilai signifikansi 0,000 lebih kecil dari 0,05 mengindikasikan bahwa $\mathrm{H}_{2}$ diterima. Hal ini berarti bahwa good corporate governance berpengaruh positif dan signifikan pada budaya organisasi berorientasi tim. Hal ini menunjukkan bahwa semakin baik penerapan good corporate governance maka budaya organisasi berorientasi tim juga akan semakin baik. Pengurus LPD dalam mengelola LPD dapat mengesampingkan kepentingan pribadi mereka hal ini sejalan dengan teori stewardship karena dengan penerapan GCG yang baik berdampak terhadap perilaku karyawan yang bertanggungjawab, berkerjasama dalam mengelola LPD. GCG memberikan suatu pedoman yang baik kepada budaya organisasi berorientasi tim karena GCG bisa memberikan suatu arahan dan didukung dengan karyawan sehingga karyawan akan memiliki motivasi meningkatkan budaya organisasi berorientasi tim. Hasil penelitian sejalan dengan hasil penelitian yang dikemukakan oleh Soraya \& Suardana (2018), Puspitha \& Sujana (2016) yang menyatakan bahwa good corporate governance terdapat pengaruh positif dan signifikan pada budaya organisasi. Hal ini sejalan dengan penelitian Indriyani \& Putra (2015), Sanjaya et al., (2019) yang menyatakan adanya pengaruh GCG pada budaya organisasi. Budaya organisasi berorientasi tim berpengaruh signifikan terhadap suatu perkembangan organisasi (Hakim, 2015).

Hipotesis ketiga menyatakan budaya organisasi berorientasi tim berpengaruh positif pada kinerja LPD. Berdasarkan hasil analisis pengaruh budaya organisasi berorientasi tim pada kinerja LPD diperoleh nilai signifikansi sebesar 0,000 dengan nilai koefisien regresi bernilai positif sebesar 0,506. Nilai signifikansi 0,000 lebih kecil dari 0,05 mengindikasikan bahwa $\mathrm{H}_{3}$ diterima. Hal 
ini berarti bahwa good corporate governance berpengaruh positif dan signifikan pada kinerja LPD. Hal ini menunjukkan bahwa semakin baik penerapan budaya organisasi berorientasi tim maka kinerja LPD juga akan semakin baik. Budaya organisasi berorientasi tim yang diterapkan oleh organisasi akan membantu pengelola dalam bertanggungjawab terhadap kinerjanya karena LPD mengutamakan kekompakan tim hal ini sesuai dengan teori penatalayanan yang menggambarkan seorang pengelola haruslah bertanggungjawab dalam mengelola suatu organisasi. Dengan menerapkan budaya organiasi berorientasi tim yang didukung oleh kejarsama antar pegawai, dukungan manajemen untuk menjaga hubungan dengan rekan kerja di anggota tim lain, dan menjaga hubungan baik antara sesama anggota pegawai akan menciptakan suasana kerja yang baik, suasana kerja yang baik akan meningkatkan kinerja pegawai sehingga akan berdampak terhadap kinerja LPD. Hasil penelitian sejalan dengan hasil penelitian yang dikemukakan oleh Mousavi et al., (2015), Ratnadi et al., (2017), Perawati \& Badera (2018), Anggiriawan \& Wirakusuma (2015), yang menunjukan hasil serupa bahwa budaya organisasi berpengaruh positif dan signifikan pada kinerja kinerja. Budaya organisasi berorientasi tim berpengaruh positif dan signifikan pada kinerja perbankan karena, kerjasama antara sesama rekan kerja dapat mempengaruhi hasil kinerja para karyawan dan akan berdampak pada peningkatan kinerja organisasi (Vij et al., 2012).

Hipotesis keempat menyatakan good corporate governance berpengaruh positif pada kinerja LPD melalui budaya organisasi berorientasi tim. Hasil perhitungan sebelumnya didapat nilai koefisien $\mathrm{a}=0,480$ ( $\operatorname{sig} \mathrm{a}=0,000)$, nilai koefisien $b=0,335$ (sig $b=0,000)$, dan nilai koefisien $c=0,506(\operatorname{sig} c=0,000)$. Berdasarkan hasil tersebut maka budaya organisasi berorientasi tim dikatakan sebagai variabel mediasi sebagian (parsial mediation), karena nilai (a) dan (c) signifikan serta (b) juga signifikan. Budaya organisasi berorientasi tim merupakan variabel yang memediasi sebagian pengaruh good corporate governance pada kinerja LPD atau dengan kata lain good corporate governance berpengaruh secara tidak langsung pada kinerja LPD melalui budaya organisasi berorientasi tim. Semakin baik GCG diterapkan, akan menyebabkan baiknya budaya organisasi berorientasi tim sehingga kinerja LPD juga akan meningkat. Penerapan tata kelola good corporate governance diharapkan dapat meningkatkan kinerja LPD melalui budaya organisasi berorientasi tim karena fenomena kecurangan akan diminimalisir dengan tata kelola yang baik sehingga akan menyebabkan para karyawan lebih terpacu dalam bekerja agar tercapainya kinerja lebih tinggi serta kinerja keuangan yang sehat. Hal ini sesuai teori agensi yaitu adanya hubungan keagenan, antara desa pekraman yang melimpahkan wewenang tugas kepada pihak pengelola LPD untuk melakukan suatu pekerjaan akan menyebabkan adanya asimetri informasi yang dapat dihindari dan diminimalisir dengan kerangka atau konsep good corporate governance (Wirawan \& Putri, 2018). Hasil penelitian sejalan dengan hasil penelitian yang dikemukakan oleh Soraya \& Suardana (2018), Indriyani \& Putra (2015), Puspitha \& Sujana (2016) yang menyatakan budaya organisasi berpengaruh positif signifikan pada good corporate governance dan berdampak terhadap kinerja. 


\section{SIMPULAN}

Berdasarkan hasil analisis dan pembahasan yang diuraikan, maka dapat disimpulkan bahwa good corporate governance berpengaruh positif pada kinerja LPD, hal ini berarti semakin baik penerapan good corporate governance dalam kegiatan LPD maka semakin baik kinerja LPD. Good corporate governance berpengaruh positif pada budaya organisasi berorientasi tim, hal ini berarti semakin baik penerapan good corporate governance maka semakin baik kualitas nilai-nilai budaya organisasi berorientasi tim karena sudah ada tata kelola yang baik mengontrol suatu organisasi. Budaya organisasi berorientasi tim berpengaruh positif pada kinerja LPD, hal ini berarti semakin baik kualitas budaya organisasi berorientasi tim maka kinerja LPD akan semakin baik. Good corporate governance berpengaruh pada kinerja LPD secara tidak langsung melalui budaya organisasi berorientasi tim, hal ini berarti semakin baik penerapan good corporate governance maka akan menyebabkan semakin baik penerapan budaya organisasi berorientasi tim sehingga kinerja LPD juga akan meningkat.

Keterbatasan penelitian ini menggunakan persepsi dalam pengukuran kinerja, peneliti selanjutnya diharapkan menggunakan rasio-rasio keuangan untuk mengukur kinerja. Serta peneliti selanjutnya yang menggunakan topik serupa dapat menggunakan variabel budaya organisasi berorientasi tim sebagai variabel moderasi. Bagi LPD, penerapan good corporate governance sudah baik namun diharapkan LPD dapat meningkatan keputusan ketua yang bersifat objektif sehingga terbebas dari kepentingan berbagai pihak yang merugikan LPD. LPD juga diharapkan semakin meningkatkan kerjasama tim dan meningkatkan layanan serta kualitas karyawan.

\section{REFERENSI}

Adiputra, I. M. P. (2014). Budaya Tri Hita Karana Sebagai Pemoderasi Pengaruh Kompleksitas Tugas Terhadap Kinerja Internal Auditor (Studi Pada Kantor Inspektorat di Provinsi Bali). Jurnal Dinamika Akuntansi, 6(2), 191-206. https:// doi.org/10.15294/jda.v6i2.3257

Anggiriawan, P. B., \& Wirakusuma, M. G. (2015). Pengaruh Gaya Kepemimpinan dan Budaya Organisasi terhadap Kinerja Organisasi dengan Penerapan Good Governance Sebagai Variabel Moderasi. E-Jurnal Akuntansi, 10(2). https://ojs.unud.ac.id/index.php/bse/article/view/19043

Astini, N. K. A. T., \& Yadnyana, I. K. (2019). Pengaruh Penerapan GCG dan Budaya Tri Hita Karana pada Kinerja Keuangan LPD Di Kabupaten Jembrana. E-Jurnal Akuntansi Universitas Udayana, 27(1), 90-118. https:// doi.org/10.24843/EJA.2019.v27.i01.p04

Atmadja, A. T., Darmawan, N. A. S., \& Saputra, K. A. K. (2014). Pengaruh Implementasi Good Corporate Governance dan Proteksi Awig-Awig Terhadap Kinerja Lembaga Perkreditan Desa (LPD) dengan Budaya Menyama Braya Sebagai Variabel Moderasi (Studi Pada LPD Se-Kabupaten Buleleng). Jurnal Ilmu Sosial Dan Humaniora, (1), 1-24.

Dasuki, R. E., \& Lestari, A. (2019). Implementation of Good Corporate Governance to The Value of Cooperative Company. Journal of Economics Empowerment Startegy (JEES), 24-41. https:// doi.org/10.30740/j.v2i1.33 
Dimitrios, B. (2014). Organizational Culture and Job Satisfaction, in Banking Sector - a Review. International Journal of Human Resources Management (IJHRM), 3(1), 15-36. https:/ / www.researchgate.net/publication/271585524 Edison, San. (2017). 150 LPD di Bali Dinyatakan Bangkrut. Bali Tribune.

Ege, I., \& Sener, Z. (2017). Balanced Scorecard in Management Accounting and its Application to Insurance Companies in Turkey. Journal of Economics, Finance and Accounting, 4(3), 215-223. http:// doi.org/10.17261/Pressacademia.2017.689

Hakim, A. (2015). Effect of Organizational Culture , Organizational Commitment to Performance : Study In Hospital Of District South Konawe Of Southeast Sulawesi. The International Journal Of Engineering And Science, 4(5), 33-41.

Hapsari, A. A. (2018). Pengaruh Good Corporate Gvernance ( GCG ) dan Corporate Social Resposibility Terhadap Nilai Perusahaan. Jurnal Bakti Masyarakat Indonesia, 1(1), 211-222. Doi: 10.24912/jbmi.v1i1.1900

Indriyani, N. M. V., \& Putra, I. W. G. Y. D. (2015). Pengaruh Good Corporate Governance Dan Budaya Tri Hita Karana Sebagai Variabel Moderasi Pada Kualitas Laporan Keuangan. Jurnal Krisna:Kumpulan Riset Akuntansi, 4(10), 91-106. http://dx.doi.org/10.22225/kr.11.2.1434.164-169

Jepkorir, E., Lagat, C., \& Ng'eno, V. (2017). Effect of Organizational Culture on Jo Performance in Commercial Banks in Kenya. International Journal of Economics, Commerce and Management United Kingdom, V(8).

Jingga, K. A. (2018). Ketua LPD Sunantaya Diduga Gelapkan Dana Nasabah. Bali Tribune.

Kamau, P., \& Wanyoike, K. (2019). Perspective Corporate culture and organizational performance: A case of Mayfair casino, Nairobi city county , Kenya Global Journal of Commerce and. Global Journal of Commerce and Management Perspective. Doi: 10.24105/gjcmp.2019.8.2

Kusumasari, P. D., Sinarwati, N. K., \& Yuniarta, G. A. (2017). Pengaruh Penerapan Prinsip-prinsip Good Corporate Governance, Komitmen Organisasi, Gaya Kepemimpinan dan Pengawasan Internal terhadap Kinerja Lembaga Perkreditan Desa (Studi Empiris pada LPD Kecamatan Ubud Kabupaten Gianyar). E-Journal S1 Ak, 7(1). http:// dx.doi.org/10.23887/jimat.v7i1.9412

Madueke, C. V., \& Emerole, I. C. (2017). Organizational Culture and Employee Retention of Selected Commercial Banks in Anambra State. Saudi Journal of Business and Management Studies, 2(3B), 244-252. Doi: 10.21276/sjbms.2017.2.3.16

Mousavi, S. A., Hosseini, S. Y., \& Hassanpour, N. (2015). On the Effects of Organizational Culture on Organizational Performance: An Iranian Experience in State Bank Branches. Irianian Journal of Management Studies (IJMS), 8(1), 97-116.

Mudashiru, A., Bakare, I. A. ., Babatunde, Y., \& Ishmael, O. (2014). Good Corporate Governance and Organisational Performance: An Empirical Analysis. International Journal of Humanities and Social Science, 4(7), 170-178.

Paramita, E., Lumbanraja, P., \& Absah, Y. (2018). The Effect of Organizational Culture and Commitment to Performance of Employees with Working Satisfaction as Moderation Variables in Pt. Bank Mandiri (Persero) Area 
Medan. Global Journal of Management and Business Research: A Administration and Management, 18(11).

https://journalofbusiness.org/index.php/GJMBR/article/view/2595

Perawati, K. M., \& Badera, I. D. N. (2018). Pengaruh Gaya Kepemimpinan Transformasional , Budaya Organisasi dan Komitmen Organisasi pada Kinerja Organisasi. E-Jurnal Akuntansi Universitas Udayana, 25(3), 1856-1883. https:// doi.org/10.24843/EJA.2018.v25.i03.p09

Pratami, L. A. R., \& Damayanthi, I. G. A. E. (2018). Budaya Organisasi Memediasi Kualitas Penerapan Sistem Informasi Akuntansi dan Kepercayaan Teknologi Informasi Pada Kinerja Karyawan. E-Jurnal Akuntansi Universitas Udayana, 22(2), 1032-1058. https:// doi.org/10.24843/EJA.2018.v22.i02.p08

Puspitha, M. Y., \& Sujana, I. K. (2016). Budaya Organisasi Pemoderasi Pengaruh Prnsip Good Corporate Governance Pada Kinerja Perusahan Berbasis Balanced Scorecard. E-Jurnal Akuntansi Universitas Udayana, 14(3), 19782012. https://ojs.unud.ac.id/index.php/Akuntansi/article/view/16086

Putra, aditya dwi. (2018). UMKM Sumbang 60 Persen ke Pertumbuhan Ekonomi. Liputan 6.com.

Ratnadi, N. M. D., Putra, I. N. W. A., \& Wirawati, N. G. P. (2017). Budaya Organisasi, Orientasi Etika dan Kinerja Keuangan Koperasi. E-Jurnal Akuntansi, 12(1), 96-111.

Risqiyah, R., Miqdad, M., \& Kartika. (2014). Pengaruh Good Corporate Governance Terhadap Kinerja Keuangan Perusahaan Pada Industri Perbankan Yang Terdaftar di Bursa Efek Indonesia. http:// repository.unej.ac.id/handle/123456789/63102

Sanchia, M. I., \& Zen, T. S. (2015). Impact of Good Corporate Governance in Corporate Performance. International Journal of Management and Applied Science, 1(9), 2394-7926.

Sandraningsih, K., \& Putri, A. (2015). Pengaruh Prinsip-Prinsip Good Corporate Governance Pada Kinerja Keuangan Lembaga Perkreditan Desa Kecamatan Abiansemal. E-Jurnal Akuntansi, 11(3), 878-893. https://ojs.unud.ac.id/index.php/Akuntansi/article/view/12997

Sanjaya, N. M. W. S., Nopiyani, P. E., \& Rianita, N. M. (2019). Kualitas Laporan Keuangan Ditinjau dari Budaya Tri Hita Karana, GCG, Kompetensi SDM dan Manajemen Risiko Lembaga Perkreditan Desa. Jurnal Riset Akuntansi Dan Keuangan, 7(3), 491-502. Doi: 10.17509/jrak.v7i3.17628

Satriyadi, I. G. H., \& Suryanawa, I. K. (2015). Pengukuran Kinerja Berbasis Balanced Scorecard pada Koperasi Pegawai PT.Telkom (KOPEGTEL) Insan Denpasar. E-Jurnal Akuntansi Universitas Udayana, 11(3), 828-847. https://ojs.unud.ac.id/index.php/ Akuntansi/article/view/12944

Sawitri, P. P., \& Ramantha, I. W. (2018). Pengaruh Penerapan Prinsip-prinsip Good Corporate Governance pada Kinerja Bank Perkreditan Rakyat di Kota Denpasar. E-Jurnal Akuntansi Universitas Udayana, 23(2), 1093-1118.

Setyawan, komang meitradi, \& Putri, I. G. A. M. A. D. (2013). Pengaruh Good Corporate Governance Terhadap Kinerja Keuangan Lembaga Pekreditan Desa Di Kecamatan Mengwi Kabupaten Badung. E-Jurnal Akuntansi, 5(3), 586-598. https:/ / doi.org/10.24843/EJA.2018.v23.i02.p11

Soraya, B. E., \& Suardana, K. A. (2018). Budaya Organisasi Sebagai Pemoderasi 
Pengaruh Good Corporate Governance pada Kinerja Keuangan Bank Pembangunan Daerah Bali. E-Jurnal Akuntansi Universitas Udayana, 23(3), 2414-2443. https:// doi.org/10.24843/EJA.2018.v23.i03.p30

Suaryana, I. G. N. A., \& Noviari, N. (2018). The Role of Supervisory Agency in the Implementation of the Implementation of Good Corporate Governance and its Implications on LPD Performance in Denpasar, Indonesia. International Journal of Economics, Commerce and Management, VI(9), 206-229.

Supriyatna, A., Rahayu, A., \& Sugiharto, M. D. (2018). Good Corporate Governance and Bank Performance: A Balanced Scorecard Approach. Jurnal Riset Akuntansi $\mathcal{E}$ Keuangan, 6(3), 481-496. http:// ejournal.upi.edu/index.php/JRAK

Vij, M. P. (2012). Impact of Job Satisfaction of Employees and Organizational Culture in Banks on Receptiveness to Change, Cooperation among Peers, Team Orientation, Organizational Goal Identity and Union Management Cooperation. IOSR Journal of Business and Management, 5(3), 47-53.

Wedantara, I. K. D. A., \& Adi, I. N. R. (2019). Kearifan Lokal Sebagai Motivasi Dalam Mingkatkan Kinerja Lembaga Perkreditan Desa Sibetan. Jurnal Manajemen Dan Bisnis, $16(1), \quad$ 58-67. http://dx.doi.org/10.38043/jmb.v16i1.2019

Widyantara, I. N., Wahyuni, M. A., \& Atmadja, A. T. (2017). Pengaruh Independensi, Motivasi, Kompetensi, dan Pengalaman Kerja Terhadap Kinerja Badan Pengawas Sebagai Auditor Internal Pada Lembaga Perkreditan Desa (LPD) di Kecamatan Buleleng. E-Journal S1 Ak Universitas Pendidikan Ganesha, 8(2). http://dx.doi.org/10.23887/jimat.v8i2.13278

Yasa, I. B. A., Parnata, I. K., \& Susilawati, N. L. N. A. S. (2018). Analytical review based on statistics on good and poor financial performance of LPD in Bangli regency. Journal of Physics: Conference Series, 953(1). Doi: 10.1088/17426596/953/1/012083

Yudana, P. I., Cipta, W., \& Suwendra, I. W. (2015). Pengaruh Kredit Bermasalah dan Perputaran Kas Terhdap Likuiditas pada Lembaga Perkreditan Desa Kecamatan Seririt. E-Journal Bisma Universitas Pendidikan Ganesha Jurusan Manajemen (Volume 3 Tahun 2015), 3(1).

Yuliantari, P. P. I., Budiasih, I. G. A. N., Ratnadi, N. M. D., \& Putra, I. N. W. A. (2020). Tri Hita Karana As a Moderating Variable of Good Corporate Governance and Crossed Credits in Financial Performance of Rural Credit Institution of Gianyar District, Indonesia. Russian Journal of Agricultural and Socio-Economic Sciences, 97(1), 56-65. Doi: 10.18551/rjoas.2020-01.07

Zaidirina, \& Lindrianasari. (2015). Corporate governance perception index , performance and value of the firm in Indonesia. Int. J. Monetary Economics and Finance, 8(4), 385-397. https://doi.org/10.1504/IJMEF.2015.073230 